\title{
Journey of a patient editor
}

Nine years ago the BMSs Tessa Richards underwent thoraco-abdominal surgery for adrenal cancer, followed by further surgery to remove metastases. Now the senior editor in charge of the journal's patient partnership agenda, she reflects on how her own experience of illness and recovery, and of joining the ranks of patients who survive the odds, have shaped her understanding of the patient perspective

\section{Tessa Richards senior editor, BMJ}

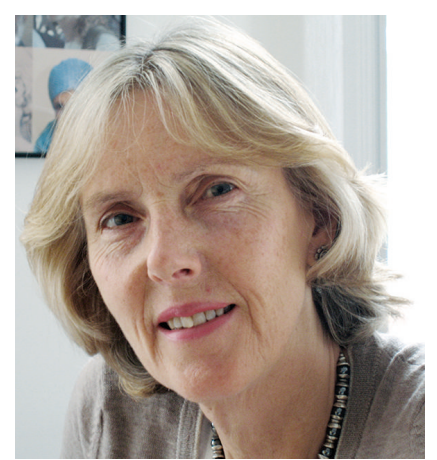

Doctors aren't good at assessing their own symptoms. They either leap to diagnose serious disease or, more commonly, go into denial. They are slow to accept that they are ill and slower still to seek help. Take the following case, for example.

In autumn 2003 I developed sharp intermittent back pain when driving or sitting for any length of time. I was also troubled by headaches. Some days I felt inordinately tired and found it difficult to work. My family advised me to go to my general practitioner. I did not follow their advice. Worse, I consulted myself.

What would you do, I asked myself, if you were a GP (as I was once), and a woman over 50 came in complaining of backache, headaches, and tiredness? A silly question, of course.

Consultations are not formulaic. In 10 minutes it's impossible to take a detailed history and conduct the full examination that such symptoms theoretically warrant. In the absence of obvious disease doctors have to act on clinical instinct after what is often a cursory initial assessment.

The symptoms I had were common, their severity difficult to gauge. I doubted that my GP would find anything amiss if he examined me or that investigations would show anything. Go for self help, I concluded: osteopath for the back, paracetamol for the head.

Three months on and life was becoming a struggle. Friends sympathised. "We all feel like that," they said, as we exchanged grumbles about teenagers, elderly parents, and work.
The spouse's patience wore thin. "Stop biting off more than you can chew," he said, "shed some commitments, and take more exercise." I tried, but my efforts were pathetic.

By January I had developed ankle swelling, which increased as the day went on, and by evening I had pitting oedema.

Paradoxically, I was relieved. Here at last was an objective physical sign. But I still failed to seek help, toiling through each day in a blinkered, donkey-like fashion.

Eventually I leant across an editorial "hot desk" and asked a wise $B M J$ friend who works in general practice for advice. She said that if I were her patient she would investigate. This prompted me to go to my GP, who listened to my complaints carefully, asked a few questions, and arranged blood tests. "And if the blood tests come back normal?" I asked. "Put your feet up when you can and wiggle your ankles," was the reply. "If the swelling gets worse come back."

A month went by. The leg swelling was unchanged, but I felt worse. I wondered if the blood tests had shown anything. It's salutary to be on the receiving end. I have often been guilty of failing to let patients know the results of tests. Doctors are geared to identify and act on abnormal results. It is all too easy to underestimate the patient's need for timely and sensitive feedback about all the tests they undergo.

I plucked up courage to ask the surgery for my blood test results. They were normal bar a minor blip of dubious significance. But by now I was worried enough to ask a colleague to recommend a general physician to go to.

\section{NHS wheels start to turn}

Doctors have a strong tradition of going out of their way to help colleagues, and to my surprise the physician my friend put me in touch with emailed me and suggested we talk. I phoned him, and after listening and asking a few penetrating questions he said I needed prompt investigation. Two days later I was in the medical outpatient department having undergone chest radiography, electrocardiography, and echocardiography. The professionalism of my new physician was outstanding. He was 
kind, considerate, and reassuring, and his meticulous examination uncovered a second "hard" sign.

"Did you know you had a big liver?" he asked. I felt incredibly stupid. I thought my abdomen may have changed shape a bit but had not worked out why. So much for my clinical acumen. "And your blood pressure is high," he said, "which may have aggravated your migraine and account for the headaches."

He prescribed antihypertensives and ordered an ultrasound scan. It was carried out on the same day, and the registrar expressed concern. The boss was called in.

"You have a large abdominal tumour," he said, "and possibly one in the pelvis too. You need a CT scan. I'm afraid this looks like cancer."

I was stunned. I'd only just grudgingly accepted that I had hypertension. I was wholly unprepared for a diagnosis of cancer.

When I saw my physician an hour later his face was grave. He gently explained the significance of the position of a massive adrenal tumour compressing the inferior vena cava. I listened in a daze as he talked about getting a surgical team together. It's not necessarily cancer, he said.

I returned home oblivious for once of the shortcomings of South East Rail. How on earth could I have been so stupid as to wander around for months with a tumour the size of a melon? Was surgery really that urgent? Was it cancer? What should I tell my family?

I mumbled something to the children to the effect that it was good that the doctors had found the cause of my symptoms and that the surgeons would sort me out. I felt totally detached, as if I were playing a part on stage: the patient with a serious problem. But on the train next morning on my way back to hospital I burst into tears. Gnawing apprehension displaced disbelief.

\section{Tough messages delivered with kindness}

Two hours later the surgeons were explaining why surgery was urgent. They judged the tumour to be life threatening by virtue of its position and that I was at high risk of a pulmonary embolus. A "nil by mouth" sign went up.

Two hours later it was taken down. Further discussion had raised the question that I may have a phaeochromocytoma. Operating without suitable drug cover might be tantamount to playing Russian roulette. The physicians persuaded the surgeons to wait for six days until this cover was in place.

Waiting was difficult but gave me time to accept that the "interesting case" with the eye catching x ray pictures was me. And to understand the surgical challenge I presented. I might not survive surgery. I pleaded to be allowed to escape from hospital for a day and had a magical 24 hour reprieve. For once I saw my family and my home for what they were and recognised my exceptional good fortune.

Back in hospital the general surgeon, vascular surgeon, and anaesthetist explained what the operation would entail. I listened but did not take in the rationale for "opening up" both the abdomen and the chest and all the technical difficulties that might be encountered. It was their frankness, positive attitude, and humane manner that I "heard," and it inspired confidence.

Other doctors popped in. Being an interesting case has its upsides. Of course I would not mind being the subject of a case report. How could I? As a doctor and medical editor I know what's grist for the mill.

I reflected on the fact that patients' wellbeing depends primarily on their doctors' judgment and clinical skill and how well they have taught and trained the teams in which they work. Yet the key factor determining their appointment to senior posts (and the financial wellbeing of their units) is "research output," measured by publications in reputable journals. How bizarre that the skills that matter most to patients seem to count for less.

In the countdown to surgery my husband's support was unstinting, and I was surprised and humbled by the concern and kindness of friends and family. Visits, calls, flowers-kind gestures that brought huge comfort. And I'll never forget the ancillary night nurse who found me sobbing in a corridor in the middle of the night, distraught at the prospect of death robbing me of the chance to bring up my children. Her warm hug, the offer of prayer, and calm advice to accept my fate helped immeasurably.

As I made the journey to theatre my thoughts were far from profound. Why did I have to be wheeled down in a chair when I could walk? Why are most hospital walls drab and faceless? Why are $50 \%$ of all hospital lifts always out of order?

Three days later, after heroic surgery complicated by massive bleeding, I went through the surreal experience of being taken off the ventilator. I was dimly aware of figures and voices speaking kindly but urgently. I tried to obey instructions from a twilight world. I couldn't speak. A slate and stylus were provided. I gripped the stylus but writing was difficult and to my frustration I wrote gibberish.

A voice reached through the haze. "You're lucky: you've got Nurse Ros today," it said. And so I was. Instantly engaging, she smiled as she said, "How soon you get out of here depends a lot on how much effort you make." A young but seasoned hand, she made the complex business of looking after a highly dependent patient on intensive care seem simple. By the end of her shift she had helped me to sit, turn over, and even stand, and she was still smiling, although clearly exhausted.

\section{ICU and a longing for blue sky}

I began to take in my surroundings: the machinery of high tech care; the nurses in perpetual motion; doctors in front of computer screens or briefly clustering at the foot of beds, exchanging the odd word with occupants who were capable of it, before diving into their office. The ward was windowless. Night resembled day, equally light, equally noisy. Every hour was punctuated by endless observations. The cacophony of bleeping machines was incessant. The stress levels of patients, relatives, and staff were palpable.

I made progress, but then a niggling temperature developed and an allergy to one of the antibiotics. One doctor suggested stopping them; another disagreed. There was talk of gastrointestinal infection. I anxiously waited for results. The realisation that I might pose an "infectious hazard" filled me with dread. The man in the next door bed was deteriorating. Was I heading the same way? The longer I stayed in intensive care the more I feared that I was not destined to escape this staging post to extinction. I longed to see blue sky again.

During these difficult days the intensive care nurses were my prop. They worked seemingly incessantly on long shifts. I learnt their life stories and they mine. Communication with the doctors, by contrast, was minimal. I was "presented" to the intensive care consultant on ward rounds by a baffling number of different junior doctors. I do not recall any of them introducing themselves, examining me, or clearly explaining the state of play. 


\section{Team work matters}

The consultants kept me broadly in the picture, but I greatly missed the exchange I had anticipated with junior staff. Then the penny dropped. I was living in the past-harking back to the time when junior doctors worked anything up to a punitive 100 hours a week. This had its advantages. We lived in the hospital mess in close, supportive companionship. The long hours were hard, and no doubt our judgment was impaired at times, but we had the chance to really get to know our patients (and vice versa) and follow their fate closely. As part of stable clinical teams we were well supported by consultants and senior nurses, from whom we learnt a lot.

The European Working Time Directive fundamentally changed the way that junior doctors work, and its merits have been debated repeatedly since its inception. Some doctors still deplore the way their juniors work and flag up problems with continuity of care and the time it takes to accrue clinical experience. As a patient it is certainly disquieting to deal with a constantly changing medical team. One of my consultants said that team members changed so rapidly that he found it hard to remember their names. Another suggested it was far from ideal that in the course of long operations junior staff may have to down tools and leave theatres.

But whatever the make-up of a clinical team, mutual respect and cooperation are surely vital. One day one of my drips became dislodged. It needed to come out, but unusually my highly competent nurse expressed worry about possible bleeding and suggested that it had "arterialised." She asked one of the doctors to take it out for her. Her request was refused; she had put it in-she had to take it out. She went to a senior nurse for help. Within minutes there was a stand-off between the nurses and doctors on unit.

I observed the ill will with amazement. I offered to take out the drip myself. In the end a senior nurse took it out, explaining as she did so that this was nothing to do with me. It was just another event in a long line of doctor-nurse disputes on the unit. I was hugely relieved when I was transferred from intensive care to a high dependency unit. The drab rooftops viewed through the grimy windows of a tower block looked good to me, and I caught a glimpse of the sun.

My optimism did not last long. The ward was overcrowded and less than clean. The nurses seemed harassed. A security officer sporting a large pistol sat sprawled in a chair in the middle of the ward; one of the patients had recently received a death threat. The patients who shouted loudest seemed to get the most attention. It was hard to know who was in charge.

Although the mechanistic aspects of care were regularly carried out-drugs given, blood pressure taken, bleeping monitors reset-personal care did not seem to be a priority. Too often I was thirsty but unable to stretch the few feet needed to reach my glass of water. I was dirty but unable to get out of a soiled gown. I tried to comply with the order to start eating but could not begin to stomach the hospital food. Pain control was not that good, and my husband noticed pressure sores developing. It was harrowing to hear the repeated nocturnal cry of "nurse, nurse" from the distressed elderly patient next to me.

\section{Compartmentalised care is tough on patients}

I remembered a debate held at the Royal College of Nursing on whether washing patients is part of a nurse's duty or not. The majority concluded it was. But the fact that it was questioned had surprised me. Recognising different skill sets is important, but for a patient the idea that personal care should be compartmentalised, with the less desirable bits delegated to the lowest in the pecking order, seemed odd.

But compartmentalisation is where we are at. In my last clinical job in a rheumatology department I saw many elderly patients with multiple intractable problems being passed like parcels between different specialists. The difficulty of seeing the whole picture, especially when notes and $\mathrm{x}$ ray pictures are missing, is huge. Patients get frustrated, upset, and confused, not least about who "their" doctor is.

It's hard to quantify the effect of continuity of care, holistic management, and the simple interventions and humane acts that make being a patient tolerable, but we should surely appreciate their value more and reward those who provide it. The kindness of two medical students who sat on my bed and talked to me as if I was a sentient being will long stay with me.

The support I received from my elder sister will also stay with me for ever. She found my washing bag and helped me wash myself and clean my teeth. She got clean mattress pads from the nurses and reordered the bed. She heaved me into a sitting position, propped up the pillows, and spoon fed me homemade soup.

When she left I felt bereft and developed mutinous thoughts. Why doesn't the NHS admit that it no longer has the capacity to provide full nursing care? Why not consider introducing a system where family, friends, or other carers formally provide the personal care that patients need?

Unoriginal, simplistic thoughts, perhaps, ungrateful too, for I have no doubt that all the staff who looked after me were well meaning and competent; but how care is delivered matters a lot when you are incapacitated and vulnerable. I owe my life to skilled surgeons, nurses, and high tech care, but what stays with me is the way in which it was delivered. The debt I owe those who identified my needs as a person as well as a patient is large. My disillusionment with a system that does not ensure that both perspectives are equally embedded within the services it provides, no less so.

My GP called to see me soon after I was discharged, weak, painfully thin, troubled with persistent abdominal pain and problems with eating, and unable to take more than a very short excursion in a wheel chair. I didn't explain why I had "gone elsewhere" to seek help, but I did say how foolish I felt about "presenting late with gross pathology." I thought he might use this as a cue for discussion, but he didn't. It crossed my mind that my case might make for a "critical event" for the practice. I'd like to think my experience offered some learning points-it certainly did for me.

\section{The next chapter}

Reading this account years on, and after two further rounds of surgery to remove metastases in the liver and lung, some of my observations read like old hat. But memories of the emotional and physical impact of each bout of surgery remain vivid.

The night before liver surgery in 2005 (partial hepatectomy, nephrectomy, and removal of a cuff of inferior vena cava) I was consumed with anxiety. I wondered why I had consented to it. My concern was compounded by a conversation with the nurse in charge of the dependent patients on the postoperative ward, whose ranks I was due to swell. I had remarked on how few staff there were on the ward. Staffing levels were indeed unacceptably low, the nurse had said, but medical staffing could do nothing about it. 
Unable to sleep, I wandered for hours along wide, deserted hospital corridors with a pillow under my arm, stopping off in empty prayer rooms (a choice of faith was on offer) and a cigarette butt strewn lobby outside the ward in vain search of a shred of comfort. I have never felt so alone or more distressed.

The operation went well (and my family are still giving blood to compensate for what was the second massive transfusion I have received). But postoperatively the epidural line fell out; this was noted, I saw later in the discharge letter, as a minor problem. The pain was agonising. I was given a morphine syringe driver, which precipitated severe vomiting. After several hours I felt moribund. Nurses and doctors, who conducted separate ward rounds, seemed to disagree on whether I was dehydrated, and there was no fluid chart to enlighten them. A medical friend visited and went into advocacy mode. Two litres of saline later, the feeling that I was about to die left.

Belt and braces postoperative abdominal radiotherapy proved much more gruelling than I had imagined. I recalled my year as an oncology registrar and realised how little I really understood about the awful side effects many patients experience.

\section{A fellow patient stiffened my resolve}

I returned to work determined to celebrate cure. Then subsequent scans repeated in 2007 showed probable lung metastases, possibly bilateral.

By then I was almost resigned. I was weary of medical interventions and repeated appraisals and tests in different specialist departments in the different hospitals I was referred to. I tried to keep a medical file but it was (and remains) incomplete and unwieldy. A far cry from a portable e-account on a memory stick. Occasionally, continuity of care broke down, and it was not clear who was following me up. I felt even more demoralised.

When it was suggested that I should go to see a thoracic surgeon to discuss whether anything could be done about the lung secondaries I felt disinclined to do so. By strange coincidence I had just been working with one such surgeon who had expressed a strongly held view, aired in a $B M J$ analysis paper I handled, ${ }^{1}$ that operating on lung secondaries in patients with abdominal tumours did them no favours. I was also hugely aware of the already massive NHS resources I had consumed. I went abroad to see friends and family. I am not sure if it was to seek a last adventure or say goodbye.
It took another medical friend and a fellow patient with adrenal cortical cancer whom I "met" online to shake me out of the doldrums. The friend kindly said that he would look at my scans to assess how they had changed over time. He concluded that the secondaries were unilateral, and operable for now but would not remain so indefinitely. The patient advised me to "go for the third op," as he had done. So I did, and lung surgery in 2008 was successful, although a persistent postoperative pneumothorax was worrying.

This time round the care on the ward was a revelation. The efficiency and esprit de corps were remarkable. I remember the shock and sadness of witnessing the last hours of a fellow patient in the adjacent bed, and the care and incredible sensitivity of the young nurse who did all she could.

I asked my nurse why things worked well on the ward. It was all down to the consultant, she said. She was not only good at her job but "understanding of the pressures we face." There was no rank pulling. "We are all made to feel valued."

\section{Being a carer can be as harrowing as being a patient}

So more lessons, luck, effective care, timely support and kindness, and, I hope, a bit more understanding of the patient perspective. I have joined the ranks of cancer patients who survive the odds. I have also added a couple of new disorders (hyperparathyroidism and pernicious anaemia) to my portfolio.

Over the same time I have accumulated considerable experience, some of it very harrowing, of being a carer for a parent who suffered and died from dementia and a son who has developed a serious chronic disease. It's taught me a quantum more about the impact of illness. And the challenge of advocating for patients when they are unable to get the help and support they need from health services. I'm left wondering: which is the harder role?

A collection of $B M J$ patient journey articles selected by the former patient editor, Peter Lapsley, shortly before he died is now available as a Kindle e-book on the Amazon website (http://amzn.to/18ijgOE).

1 Treasure T, Utley M, Hunt I. When professional opinion is not enough. BMJ 2007;334:831.

Cite this as: BMJ 2013;347:f6913

๑) BMJ Publishing Group Ltd 2013 